\title{
Demographic diversity and the ethnic consequences of immigration - key issues that the Commission's report left out
}

\author{
David A. Coleman*
}

The European Commission's (2006) report on the 'Demographic future of Europe and its implications for its economy and society' gives first place, as usual, to population ageing and other familiar topics which will be dealt with by others in this volume. Here, comments will be offered on some of the key issues affecting the demographic future of Europe, on demographic diversity and on the effects of immigration, which the report neglected to mention.

\section{European diversity}

Demographically and from some other points of view there is really no such thing as 'Europe'. To pretend otherwise ignores radical differences across the continent in fertility rates, household and family patterns, and immigration. Those create divergent national prospects in population size and ageing, therefore in the nature of the problems to be faced and the policies appropriate for their management. Those demographic differences interact, usually unfavourably, with varied levels of workforce participation, patterns of retirement, pensions funding and levels of pension compensation. Countries with depressing demographic performances tend also to be least well equipped to manage those problems through labour market flexibility and retirement reform. These distinctions follow long-standing cultural, political and economic boundaries (Reher 1998; Lesthaeghe and Neels 2002).

The accession to the European Union of the new counties from central and eastern Europe has greatly increased this diversity and thereby the problems of making any meaningful statements about 'European' demographic challenges or the 'European' policies suitable to respond to them. That is true a fortiori of Bulgaria and Romania, whose premature accession at such a low level of economic and political reform clearly owed more to 'political vision' than to any practical considerations of Community coherence.

While the central European countries and the Baltic States, especially Estonia, have made an impressive economic recovery and often showed exemplary

\footnotetext{
* David A. Coleman, Oxford Centre for Population Research, Barnett House 32, Wellington Square, Oxford, Oxfordshire OX1 2ER, UK. Email: david.coleman@socres.ox.ac.uk
} 
openness to new ideas for economic and fiscal reform, their depressed fertility rates remain in an uncertain state of transition and their political systems still show disturbing signs of democratic immaturity. Eastern Europe especially is suffering a painful transition from 'Red' to 'Grey' (Chawla et al. 2007), as inadequate socio-economic reform and recovery from the distortions of half a century of communism, confront rapid demographic change. Many countries in the region lose population by natural decline, and most also through net emigration, although there are inflows from even poorer countries further east. Poland, the Czech Republic, Hungary, the furthest forward in reform, have begun to recover from the high male adult death rates that were a hallmark of eastern European socialism since the 1960s. Further east, political and economic reform is more tenuous. The populations of Romania and Bulgaria are falling fast under very low birth rates, high death rates and emigration that threaten depopulation by $35 \%$ in the case of Bulgaria by mid-century. Some, notably Poland, have impoverished rural populations of exceptional size unknown elsewhere in the Union, and 30\% youth unemployment in 2006 .

The consequences of this variety of demographic patterns in propelling Europe's populations and their structures in different directions is shown in Figure 1, which shows the future projected size of selected European counties to mid-century, all set at 100 in 2004 according to the Eurostat 2004-based baseline projection. However, Eurostat, like the United Nations, has tended to underestimate immigration and does not sufficiently recognise diversity in birth rates. For comparison therefore the national projections for France and the UK are also given, which envisage considerably higher totals. The projected declines of Bulgaria and Hungary are well known. At the other end of the scale the Irish Republic and Norway may increase by $30 \%$ or more. Major countries also diverge. Germany and Italy decline despite their substantial immigration. On the other hand both France and the UK are projected to grow nearly neck and neck by $10 \%$ over the half century by over 5 million people, with Sweden increasing by $14 \%$ (rather more, according to the Swedish CBS). INSEE and GAD projections for France and the UK assume larger increases of $15 \%$, in each case. Several of these northwest European countries are projected to continue to increase in population size up to mid-century and, in the case of the UK, up to 2074, and this UK 'principal' projection assumes future levels of migration and fertility to be substantially less than the current actual levels.

The Commission's report does show awareness of the diversity among the EU Member States in a few places, e.g. p.6, but for the most part its remarks are addressed to 'Europe'. Perhaps that is inevitable in a short document written on the authority of a bureaucracy necessarily committed to an 'ever-closer union' of the Member States, but as a consequence a sense of unreality pervades the report. One example of that, reflecting also the Commission's view of the powers of national governments, is the comment on p.11 emphasising the undesirability, indeed unsustainability of different national policies on immigration. However, 
national demographic and socio-economic diversity argues for their retention, quite apart from any consideration due to the desires of the inhabitants.

\section{Figure 1:}

Population trends in selected European countries, 2004-2051 (2004=100)

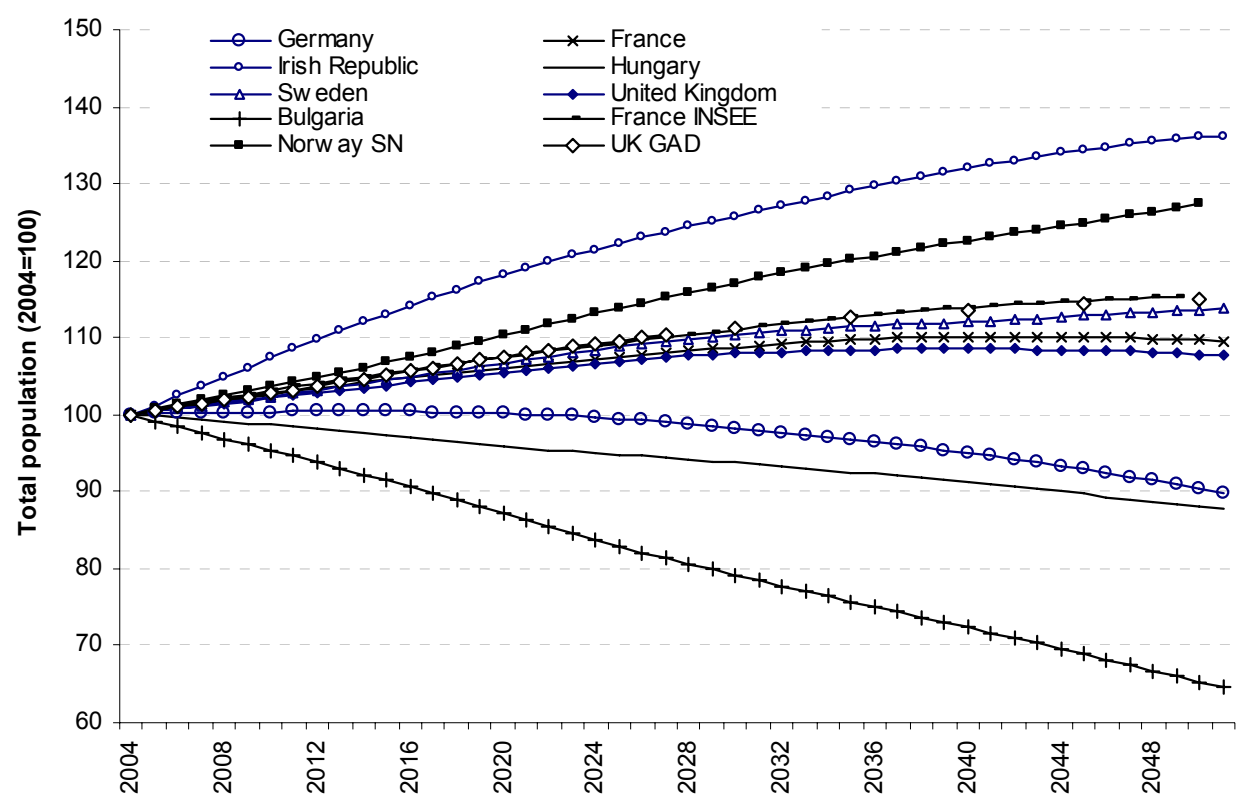

Sources: Eurostat 2004 baseline projection and national statistical offices

These divergent trends in total population, arising from contrasting rates of fertility and migration, are significant for a variety of reasons. Over a few decades, relative rank-orders of population will change, with consequences for economic and political weight in the international order (McNicoll 1999), including shifting the rank-order of size in the EU. And smaller countries such as Bulgaria and Hungary fear damaging depopulation, although Eurostat does not predict such a fate for the even more vulnerable Baltic States.

\section{The 'need' for large-scale international migration}

The report notes (p.4) that the EU already receives very large numbers of immigrants (1.8 million in 2004) and assumes that immigration will continue at a high level, citing the Eurostat projection of a further 40 million immigrants between now and 2050. It asserts that 'the total number of persons in work is set to decrease by 30 million between the end of the decade and 2050' (p.5) but neglects to note that the adoption of Danish levels of workforce participation would add 32 million. That can, of course, only be done once (Lesthaeghe 2002). The report is sensibly cautious about the likely demographic benefits and contributions to the pensions and other questions of old-age dependency arising 
from immigration (p.5), avoiding previous misunderstandings (Teitelbaum 2004). It goes on to state, however, that the continuation of significant net immigration into Europe 'must be acknowledged' (p.11). Nothing new in that; such a view is widely, though not universally, held among demographers.

The report is uncritical, however, concerning the economic need for migrants, claiming that 'the European labour market...will need to attract a qualified labour force from outside' and 'the need for external unskilled labour will also remain very high' (p.11). This may be true in some EU countries if their very low levels of workforce participation are allowed to persist. But insistence on a continued or increased reliance on immigrant workers assumes the failure of essential reforms, specified elsewhere, to increase workforce participation, reduce segmented labour markets, encourage later retirement and increase productivity. It also assumes the failure of education systems in bringing forward a suitably skilled labour force. In some EU countries scarcely half the population of nominal working age has a job. Belgium, France, Finland, Greece, Italy, Spain and other EU countries all have persistent youth unemployment rates of over $20 \%$ - the figure was $16 \%$ in the EU-15 as a whole in 2006. Importing cheap and willing labour from overseas is a temporarily convenient way of evading that problem. The difficulties of reforming welfare arrangements and labour protection in the teeth of the vested interests of the 'European Social Model', and the unattractiveness to employers of many of the unemployed make this short-term response understandable but dangerous, for security as well as national prosperity. European countries can only prosper in the long run if they follow the road to knowledge-based high productivity and high-wage economies. As the rest of the world develops, reliance on other nations' skills, already morally dubious (Rowthorn 2006) will eventually cease even to be an option.

Migration for labour and other purposes has always been a normal feature of relations between open societies. Clearly it is desirable to fill vacancies that arise through frictional flaws in the economy, the labour mobility needs of multinationals, temporary mismatches between domestic supply and demand in fast growing sectors. But if that supply is allowed to dominate important economic sectors or discourage the training of the domestic population, then the economy becomes distorted and dependent upon migration. The nationalised National Health Service in the UK has only been able to continue in its unreformed and chronically underfunded state thanks to the contributions of overseas staff, who (uniquely in Europe) comprise one third of its total of doctors and many of its nurses.

The report assumes general benefits from migration. In the huge literature on that subject most studies can show some benefits. These vary according to the country studied and the assumptions used. Most accrue to the immigrants themselves. The overall net benefit is usually small, occasionally negative, and very unevenly spread in the economy and society. Immigrants themselves gain, as do their employers and the consumers of services. Poorer elements of the society 
are likely to lose. Overall, for example, the claims advanced by the UK government in support of its positive immigration policy can be shown on its own figures to be of the order of about 50p per week per person (under 1 Euro), or on some calculations, negative (Coleman and Rowthorn 2004). And these calculations do not put in the balance the costs associated with health, education, crime and security, nor those of the immigration industry itself; its translators, social workers, race relations officers, multicultural subsidies and the rest. Naturally immigration increases overall GDP because it increases the population. Whether it can increase per capita GDP, the measure of individual welfare, is a different matter. Most immigrants to Europe in recent decades have not entered specifically for work but as spouses, dependants, students or asylum seekers. While those may work, it is not surprising that levels of unemployment among immigrants and their descendants are typically about double those of natives (Causa and Jean 2006), and workforce participation is usually lower.

\section{The demographic and ethnic consequences of large-scale immigration}

One of the most important aspects of the demographic future of Europe is not mentioned at all in the report (or indeed in other similar publications) even though it is implicit in the continued large-scale immigration which the report endorses. If continued, that immigration would have a powerful, cumulative and permanent effect upon the composition according to national origin or 'ethnicity' of the population of European countries, progressively diminishing the share of the native or indigenous population over time. Some population projections have treated migration inflows and outflows, and fertility rates, separately according to various national origins. In that way their impact on the composition of the population, given the continuation of specified, usually current migration trends, and convergent assumptions of fertility rates, can be estimated. Projections of this kind, mostly official, have been made for Austria, Denmark, Germany, the Netherlands, Norway, Sweden and the United Kingdom (and outside Europe, for the United States and New Zealand). These are reviewed elsewhere (Coleman 2006). In most of the projections the foreign-origin population is defined to include both the first immigrant generation and the second generation born in the host country, on criteria that differ slightly between countries. The third generation is generally assumed to be assimilated to the national population and to become Dutch, Swedish etc, thus disappearing from statistical view. However, potentially permanent 'ethnic' categories are employed in the projections for the English-speaking countries.

On those conservative assumptions, the foreign-origin proportions of those populations are projected to rise to between about $15 \%$ to over $30 \%$ by midcentury with almost linear rates of change (Figure 2). The proportion of the foreign-origin populations with non-European backgrounds is expected to increase from about one half today to about two thirds by mid-century, up to $20 \%$ of the total population. The composition of the population by origin does not 
necessarily determine the degree of social or economic salience of these differences. That would depend upon the degree of integration and social assimilation, including inter-ethnic union.

\section{Figure 2:}

Projected growth of population of immigrant or foreign origin as per cent of total population in selected countries of Europe, 2000-2050

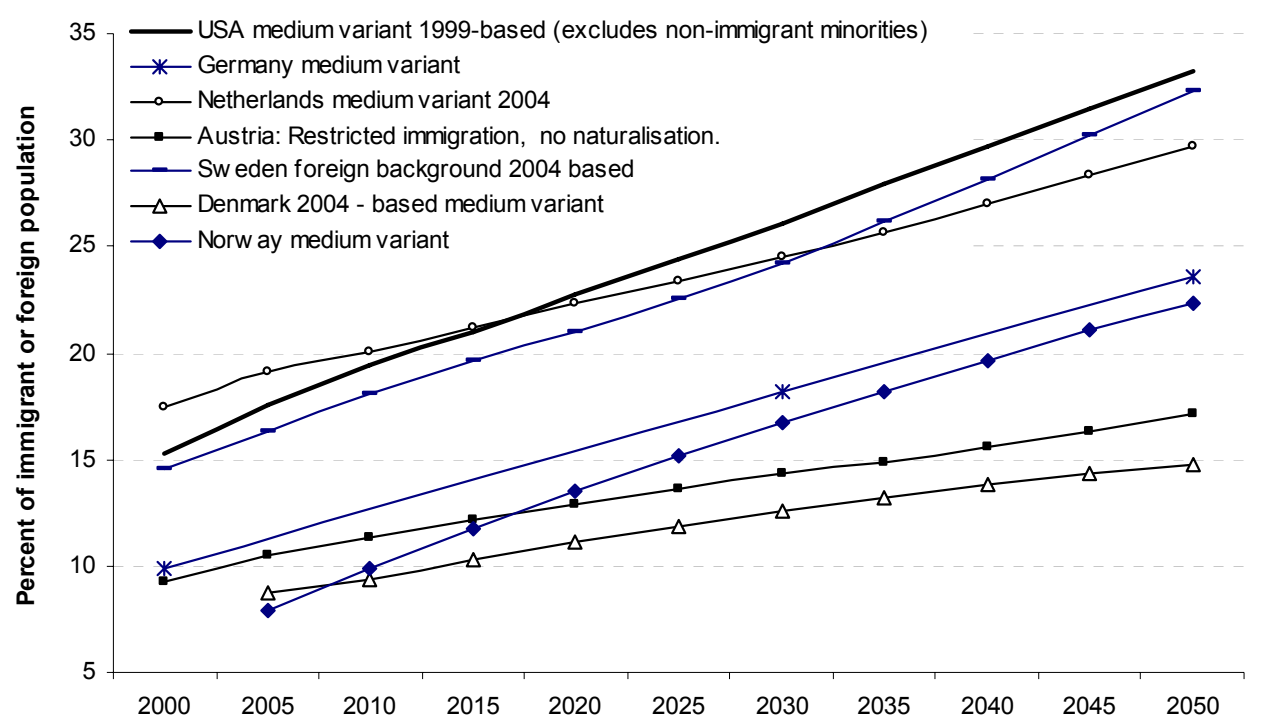

A high prevalence of inter-ethnic unions would moderate the growth of immigrant-origin populations strictly defined, while introducing a new diversity from rapidly growing heterogeneous mixed-origin populations. These may eventually defy categorisation and become a very numerous if diffuse population. If continued further to the end of the century and beyond, immigration combined with below-replacement fertility would lead to the eventual displacement of the original population from its majority position. The possible marginalisation of European populations in Europe might be thought rather a rather momentous prospect, and a proper concern of policy, especially if it were an unintended consequence of policies entered into for other ends.

Migration assumptions are more important than fertility assumptions in determining this outcome. The projected ethnic change-based on unchanged migration flows - is therefore by no means inevitable but depends on migration policy as well as on many unpredictable developments. Although in current circumstances migration is much easier to encourage than to limit, it can go down as well as up, as a number of governments have shown.

There is widespread public concern about the scale of migration and its effects, on the economy, the labour market, social cohesion and national culture, 
crime and security. Across 21 countries, according to the European Social Survey 2004/5, small majorities think that immigration is not good for the economy and does not make their county a better place to live in (although it does enrich it culturally). A majority of nearly three to one would admit only a few immigrants of a different ethnic group compared with those that would admit many, while a small majority oppose the entry even of many immigrants of their own ethnic group (Jowell et al. 2005).

Some of these concerns are well-founded, others are not. But the report (p.11) merely comments on the need to 'inform public opinion and combat prejudice' and 'respect differences' and 'point out the riches of diversity'. Pious comments of that kind will command universal agreement only where those differences can indeed be respected in a secular liberal society. Even the European Commission must have noticed that some cannot be, for reasons cogently outlined, for example, by Francis Fukuyama (2007). Blandly ignoring disquiet, rather than responding to it, does not encourage rational policy making and must persuade many Europeans that the EU commission lives on a different planet.

\section{References}

Causa, O. and S. Jean. 2006. "Immigrants' Integration in OECD countries: does labour market policy matter?" OECD draft working paper December 2006. Paris, OECD.

Chawla, M., G. Betcherman, et al. 2007. From Red to Gray: the 'third transition' of aging populations in Eastern Europe and the Former Soviet Union (overview). Washington DC, The World Bank.

Coleman, D. A. 2006. "Immigration and Ethnic Change in Low-Fertility Countries. A third demographic transition." Population and Development Review 32(3): 401 - 446.

Coleman, D. A. and R. Rowthorn. 2004. "The Economic Effects of Immigration to the United Kingdom.” Population and Development Review 30(4): 579-622.

Coppel, J., J.-C. Dumond, et al. 2001. "Trends in Immigration and Economic Consequences." Economics Department Working Paper 284. Paris, OECD.

European Commission. 2006. The demographic future of Europe - From challenge to opportunity, Communication of 12 October 2006 [COM (2006) 571]. Available at «http://ec.europa.eu/employment_social/news/2006/oct/demography_en.pdf».

Fukuyama, F. 2007. Identity and migration. Prospect, February 2007, 26-31. «http://www.prospect-magazine.co.uk/article_details.php?id=8239»

Jowell, R. et al. 2005. "European Social Surveys 2004/2005." Technical Report ESS Round 2. London, Centre for Comparative Social Surveys, City University.

Lesthaeghe, R. 2002. "Europe's demographic issues: fertility, household formation and replacement migration." Population Bulletin of the United Nations. Special issue. Policy Responses to Population Ageing and Decline 44/45: 385 - 423.

Lesthaeghe, R. and K. Neels. 2002. "Géographie de la fécondité: les cartes, l'histoire et l'innovation démographique”. In.: G. Caselli, J. Vallin and G. Wunsch (eds.) Démographie: analyse et synthèse, Volume II Les déterminants de la fécondité. Paris, INED, pp. 375 - 405. 
McNicoll, G. 1999. "Population Weights in the International Order." Population and Development Review 25(3): 411 - 442.

Reher, D. S. 1998. "Family Ties in Western Europe: Persistent Contrasts." Population and Development Review 24(2): 203 - 234.

Rowthorn, R. 2006. Cherry-picking: a dubious practice. Immigration Futures International Forum. Prato, Italy.

Teitelbaum, M. S. 2004. "The media marketplace for garbled demography." Population and Development Review 30(2): 317-327. 